\title{
MEMBANGUN KEMANDIRIAN BELAJAR SISWA DENGAN METODE KOOPERATIF STAD
}

\author{
Fakihatul Ulya Fitri \\ Program Studi Pendidikan Guru Sekolah Dasar \\ Fakultas Keguruan dan Ilmu Pendidikan \\ Universitas Nahdlatul Ulama Sidoarjo \\ Email: fakihatululya@gmail.com
}

\section{Pengantar}

Siswa adalah orang yang dengan sengaja belajar di sekolah untuk mengembangkan potensi diri melalui proses pembelajaran pada suatu jalur pendidikan formal (dari tingkat sekolah dasar, sekolah menengah pertama, dan sekolah menengah ke atas), maupun nonformal (Indah, 2014). Dan kemandirian adalah hal atau keadaan dapat berdiri sendiri tanpa bergantung pada orang lain(KBBI, 2018).

Kemandirianbelajarmerupakan suatu usaha yang dilakukanuntuk melakukan aktivitas belajardengan cara mandiri atas dasarmotivasinya sendiri untuk menguasaisuatu materi tertentu sehingga bisadipakai untuk memecahkan masalahyang sedang dihadapi. Sehingga dalamkemandirian belajar, seorang siswa harusproaktifserta tidak tergantungpada guru (Asep, 2016). Dalam hal ini untuk menjalankan segala tindakan yang berhubungan dengan pembelajaran saat ini sangat dibutuhkan kemandirian belajar siswa yang mana hal tersebut dapat menunjang siswa untuk mengingat setiap materi pelajaran yang diberikan oleh guru atau pendidik. Hal tersebut juga membantu siswa memecahkan soal-soal yang disampaikan guru secara langsung atau melalui media pembelajaran. Selain itu menurut (Asep, 2016) menjelaskan bahwa kemandirian belajar siswa akan menuntut mereka untuk aktif baik sebelum dan sesudah proses pembelajaran berlangsung. Siswa yang mandiri akan mempersiapkan materi yang akan dipelajari. Sesudah prosespembelajaran selesai, siswa akan belajar kembali mengenai materi yang sudah disampaikan dengan cara membaca atau berdiskusi. Sehingga siswa yang menerapkan belajar mandiri akan mendapat prestasi lebih baik jika dibandingkan dengan siswa yang tidak menerapkan prinsip mandiri. 


\section{Pembelajaran}

Belajar dan pembelajaran memiliki makna yang berbeda, belajarialah usaha memperoleh informasi atau pengalaman. Dengan belajar seseorang dapat memiliki pengetahuan lebih atau dari yang tidak mengetahui suatu hal menjadi tau. Sedangkan menurut(Hanafi, 2014) pembelajaran merupakan usaha pendidik untuk mewujudkan terjadinya proses pemerolehan pengetahuan, penguasaan kemahiran, dan pembentukan sikap dan kepercayaan pada peserta didik. Dengan kata lain, pembelajaran adalah proses yang menfasilitasi pesertadidik agar dapat belajar dengan baik.

\begin{tabular}{|l|l|l||}
\hline No & \multicolumn{1}{|c|}{ Teori Belajar } & \multicolumn{1}{c|}{ Teori Pembelajaran } \\
\hline 1 & $\begin{array}{l}\text { Tujuan utamanya memerikan proses } \\
\text { belajar }\end{array}$ & $\begin{array}{l}\text { Tujuan utamanya meneta plan me tode } \\
\text { pengajaran yang optimal }\end{array}$ \\
\hline 2 & $\begin{array}{l}\text { Menaruh perhatian pada bagaimana } \\
\text { seseorang belajar }\end{array}$ & $\begin{array}{l}\text { Menaruh perhatian pada bagaimana } \\
\text { seseorang mempengaruhi orang lain } \\
\text { agar terjadi hal belajar }\end{array}$ \\
\hline 3 & $\begin{array}{l}\text { Berfokus pada hubungan diantara } \\
\text { variable variable yang menentukan } \\
\text { hasil belajar }\end{array}$ & $\begin{array}{l}\text { Berfokus pada upaya mengontrol } \\
\text { variable variable yang dispesifikasi } \\
\text { dalam te ori belajar agar dapat } \\
\text { memudahkan belajar }\end{array}$ \\
\hline 4 & $\begin{array}{l}\text { Tidak berhubungan dengan metode } \\
\text { pembelajaran }\end{array}$ & $\begin{array}{l}\text { Selalu menyebutkan metode } \\
\text { pembelajaran }\end{array}$ \\
\hline 5 & $\begin{array}{l}\text { Penelitian dilakukan oleh ilmuwan } \\
\text { karena merupakan penelitian dasar }\end{array}$ & $\begin{array}{l}\text { Penelitian dasar dilakukan oleh } \\
\text { ilmuran dan penelitian terapan } \\
\text { dilakukan oleh teknolog }\end{array}$ \\
\hline 6 & $\begin{array}{l}\text { Mengungkapkan hubungan kegiatan } \\
\text { si belajar dengan proses proses } \\
\text { psikologis dalam diri si belajar } \\
\text { (mengungkapkan hubungan antar } \\
\text { fenomena yang ada dalam diri si } \\
\text { belajar) }\end{array}$ & $\begin{array}{l}\text { Mengungkapkan hubungan antara } \\
\text { kegia tan pembelajaran dengan proses } \\
\text { proses psikologi dalam diri si belajar }\end{array}$ \\
\hline 7 & $\begin{array}{l}\text { Salah satu contoh teori belajar } \\
\text { adalah Teori apersepsi yang } \\
\text { menganggap belajar merupakan } \\
\text { suatu proses tera sosiasinya gagasan } \\
\text { gagasan baru dengan gagasan } \\
\text { gagasan lama yang sudah } \\
\text { membentuk pikiran }\end{array}$ & $\begin{array}{l}\text { Contoh teori pembelajaran: teori } \\
\text { elaborasi yang dihasilkan dari pengujian } \\
\text { keefktifan strategi pengorganisasian } \\
\text { pengajaran }\end{array}$ \\
\hline
\end{tabular}

Gambar 1. Perbedaan Teori Belajar dan Pembelajaran (Riyan, 2015)

Dari tabel diatasa dapat dilihat bahwa belajar dan pembelajaran memiliki makna yang berbeda, namun kedua hal tersebut menyandang keterlibatan satu dengan yang lain. Dalam pembelajaran terjadi proses belajar mengajar, yang mana belajar merupakan kegiatan siswa untuk memperoleh suatu informasi dariguru sebagai pengajar. Untuk mendapatkan hasil terbaik dalam proses pembelajaran, guru dan siswa diharapkan memiliki interaksi yang aktif.Yang dimaksudkan dalam hal ini yaitu siswa diharapkan ikut berperan aktif dalam 
proses pembelajaran dantidak hanyamencermati apa yang diucapkan guru. Dengan begitu, siswa akan lebih mampu memahami segala sesuatu yang disampaikan. Dalam hal ini pula guru tidak harus menjadi yang dominan, yang hanya memberikan informasi saja. Saat ini diharapkan guru juga menjadi fasilitator yang membantu menfasilitasi siswa dengan segala sesuatu yang diperlukan saat proses pembelajaran berlangsung. Selain guru, model atau metode pembelajaran yang akan digunakan perlu di perhatikan. Menurut(Suci, dkk., 2018) menyatakanbahwa "thechosenlearningmodel shouldfocusontheneedsofthechildand not tofacilitatetheteachingteacher. Mathematicslearning model onlyfacilitatetheteacher, butalsoknowabouttheneedsofchildren, sothatchildrencanbeinterestedandthe spiritoflearningandable

countingtobeabletoachievethecompetenceoflearningeffectivelyandefficiently".

Maksud pernyataan tersebut adalah bahwa model pembelajaran yang digunakan harus menitikberatkan dengan segala yang dibutuhkan oleh anak bukan guru. Selain itu, model pembelajaran tersebut juga harus bisa menarik anak untuk semangat dalam belajar agar mencapai kompetensi belajar yang sesuai.Berbagai macam metode atau model dapat diterapkan dalam berlangsungnya proses pembelajaran seperti: metode ceramah, metode diskusi, metode kooperatif, metode tanya jawab, metodedemontrasi, metode latihan (drill), dll.

\section{Kooperatif STAD}

Kooperatif pribadinya ialah metode atau model yang dapat diterapkan dalam proses pembelajaran. Dalam (KBBI, 2018) menjelaskan bahwa kooperatif ialah bersifat kerja sama. Sedangkan (Herdian, 2009) menyatakan bahwa StudentTeamsAchievementDivision (STAD) merupakan salah satu metode atau pendekatan dalam pembelajaran kooperatif yang sederhana dan baik untuk guru yang baru mulai menggunakan pendekatan kooperatif dalam kelas, STAD juga merupakan suatu metode pembelajaran kooperatif yang efektif.Pembelajaran kooperatiftipe staddapat menjadi pola, metode atau teknik yang sering digunakan saat ini. Metode ini memiliki 5 unsur utama yaitu: penyampaian materi dalam kelas oleh guru, belajar dalam sebuah kelompok (diskusi), kuis atau game, skor pengembangan dan yang terakhir penghargaan kelompok. Hal-hal tersebut merupakan metode yang dapat membantu anak untuk mandiri, yang dapat membantu anak dalam menyelesaikan pertanyaan yang disampaikan guru dengan cara yang mereka bisa. Metode tersebut juga dapat membantu dalam daya ingat anak, karena anak berperan langsung dalam memecahakansoal yang diberikan oleh guru. 
Dalam metode ini gurumenjadi fasilitator yang membantu dalam kelangsunganpembelajaran. Berikut ini disajikan table fase-fase atau tahap pembelajaran Kooperatif tipe STAD:

\begin{tabular}{|c|c|}
\hline Fase & Kegiatan Guru \\
\hline $\begin{array}{c}\text { Fenyampaikan tujuan } \\
\text { dan memotivasi siwa }\end{array}$ & $\begin{array}{c}\text { Menyampaikansemua tujuan pembelajaran } \\
\text { yang ingin dicapai pada pembelajaran } \\
\text { tersebut dan memotivasi siswa belajar }\end{array}$ \\
\hline $\begin{array}{c}\text { Fase 2 } \\
\text { Menyajikan / } \\
\text { menyampaikan } \\
\text { informasi }\end{array}$ & $\begin{array}{c}\text { Menyajikan informasi kepada siswa } \\
\text { dengan jalanmendemonstrasikan ataulewat } \\
\text { bahan bacaan }\end{array}$ \\
\hline $\begin{array}{c}\text { Fase 3 } \\
\text { Mengorganisasikan } \\
\text { siswa dalam } \\
\text { kelompok-kelompok } \\
\text { belajar }\end{array}$ & $\begin{array}{c}\text { Menjelaskan kepada siswa bagaimana } \\
\text { caranyamembentuk kelompok belajar dan } \\
\text { membantu setiap kelompok agar } \\
\text { melakukan transisi secara efisien }\end{array}$ \\
\hline $\begin{array}{c}\text { Fase 4 } \\
\text { Membimbing } \\
\text { kelompok bekerja dan } \\
\text { belajar }\end{array}$ & $\begin{array}{c}\text { Membimbing kelompok-kelompok belajar } \\
\text { pada saat mereka mengerjakan tugas } \\
\text { mereka }\end{array}$ \\
\hline $\begin{array}{c}\text { Fase 5 } \\
\text { Evaluasi }\end{array}$ & $\begin{array}{c}\text { Mengevaluasi hasil belajar tentang materi } \\
\text { yang telah diajarkan atau masing-masing } \\
\text { kelompok mempresentasikan hasil } \\
\text { kerjanya }\end{array}$ \\
\hline $\begin{array}{c}\text { Fase 6 } \\
\text { penghargaan }\end{array}$ & $\begin{array}{c}\text { Mencari cara-cara untuk menghargai baik } \\
\text { upaya maupun hasil belajar individu dan } \\
\text { kelompok }\end{array}$ \\
\hline
\end{tabular}

Gambar 2. Fase-fase pembelajaran kooperatif tipe STAD

Dalam menciptakan siswa yang berkualitas,pembaharuan metode dalam pembelajaran sangat diperlukan. (Maula, dkk., 2018) menjelaskan bahwa lembaga pendidikan hendaknya tidak hanya puas dengan metode dan teknik lama, yang menekankan pada metode hafalan, sehingga tidak atau kurang ada maknanya jika diterapkna pada masa sekarang.Perkembangan jaman yang begitu pesat dewasa ini membuat siswa semakin akrab dengan berbagai hal yang baru, seiring dengan perkembangan dunia informasi dan komunikasi. Karena itu, sangat wajar jika kondisi ini harusdiperhatikan oleh guru agar terus mengadakan pembaharuan (inovasi). 


\section{Penutup}

Menciptakansiswa-siswa berkualitas merupakan cita-cita setiap lembaga pendidikan. Dalam menciptakan siswa berkualitas dibutuhkan metode-metode yang dapat membantu proses pembelajaran dan kemandirian belajar bagi siswa. Menggunakan model atau tekni yang sesuai, siswa akan dengan mudah menerima berbagai informasi yang diberikan oleh guru. Selain itu, hal tersebut juga membantu memecahkan atau menyelesaikan segala persoalan yang diberikan. Dalam hal ini, guru mempunyai kedudukan penting dalam berlangsungnya proses pembelajaran dan metode yang ingin di terapkan.(Sofwan, 2009) menjelaskan bahwa sekolah dikatakan unggul jika benar-benar menunjukan "thebestprocess", bukannya "thebestinput", yakni keunggulan dalam proses belajar mengajar.

\section{Daftar Pustaka}

Egok, A.S. (2016, Dec 2). Kemampuan Berpikir Kritis dan Kemandirian Belajar dengan Hasil Belajar Matematika. RetrivedDecember 29, 2018, from http://http://eprints.ums.ac.id/28503/

Hanafy, M.S. (2014, 1 Jun). 66 Konsep Belajar dan Pembelajaran. RetrievedDecember 29, 2018, fromhttp://http://ibn.adreach.co/interstitial?orgUrl=http\%3A\%2F\%2Fjournal.uinalauddin.ac.id\%2Findex.php\%2Flentera_pendidikan $\% 2$ Farticle $\% 2$ FviewFile $\% 2 \mathrm{~F}$ 516\%2F491\&adsTransactionId=D1046162024575234\&interstitialTimeout=7\&wi $\mathrm{dth}=320 \&$ height $=480 \& \mathrm{i}=173953579 \&$ clickUrl=http $\% 3 \mathrm{~A} \% 2 \mathrm{~F} \% 2 \mathrm{Fibn}$. adreach.co \%3A80\%2Fadsclick\%3F\%26adsTransactionId\%3DD1046162024575234\%26targ etUrl\%3Dhttps\%253A\%252F\%252Fwww.axisnet.id\%252Fpromo\%252Ffantaxis \%26orgUrl\%3Dhttp\%253A\%252F\%252Fjournal.uinlauddin.ac.id\%252Findex.php\%252Flentera_pendidikan\%252Farticle\%252Fview File\%252F516\%252F491\%26i\%3D173953579\&beaconUrl=

Herdian. (2009, Apr 22). Model Pembelajaran STAD (StudentTeamsAchievementDivision). RetrievedDecember 30, 2018,fromhttps://www.google.com/amp/s/herdy07.wordpress.com/2009/04/22/mo del-pembelajaran-stad-student-teams-achievement-division/amp/

KBBI.Mandiri. RetrievedDecember 29, 2018,fromhttp://kbbi.web.id/mandiri.html Manaf, S. (2009, Jun 12). Membentuk Siswa Unggul yang Berkualitas. Retrieved December 30, 2008, fromhttp://sofwanmanaf.wordpress.com/tag/siswa-yangunggul-dan-berkualitas/ 
Maula, I., et al. (2018). Kontribusi Kreativitas Guru SD dalam Induksi Pembelajaran. Retrieved Desember 30, 2018, from https://osf.io/preprints/inarxiv/ap3zt/

Novitasari, I. (2014, march). Upaya Guru dalam Meningkatkan Keberanian Siswa untuk Bertanya pada Pembelajaran Pendidikan Kewarganegaraan. RetrivedDecember 29, 2018, fromhttp://eprints.ums.ac.id/28503/

Suci, S. H. A., et al. (2018). Learning from Picture and Picture Action Research: Enhancement of Counting Ability on Division of Numbers for Primary School Students. Retrieved December 30, 2018, from http://iopscience.iop.org/article/10.1088/1742-6596/1114/1/012044

Wijayanti, S. (2009, Sep 16). Model Pembelajaran Kooperatif Stad. RetrievedDecember 30, 2018, fromhttp://www.google.co.id/url?Sa=t\&source=web\&rct=j\&url=http://lib.unnes.a c.id/ 